\title{
Failure of Anti-D Immunoglobulin Injection to Protect against Rhesus Immunization after Massive Foeto-maternal Haemorrhage. Report of 4 Cases
}

\author{
C. DUDOK DE WIT,* M.D.; ELS BORST-EILERS,* M.D.
}

Brit. med. F., 1968, 1, 152-15.1

The possibility of protecting women against rhesus immunization by the administration of anti-D immunoglobulin shortly after delivery has lately received considerable attention. The combined results of several recent clinical trials with this form of treatment have been summarized by Clarke (1967): of 628 women who received prophylactic treatment only one developed rhesus antibodies, whereas 75 cases of immunization were found among 599 women in the control group.

It has been shown that rhesus immunization is generally caused by small amounts (less than $1 \mathrm{ml}$.) of foetal blood that enter the maternal circulation during labour. Rarely, however, very large foeto-maternal haemorrhages occur, and it is important to know if anti-D immunoglobulin prophylaxis is also effective in these cases. Only one case has been described in which a woman with a large transplacental haemorrhage was treated, and in that instance no immunization occurred.

While conducting a clinical trial on the effect of anti-D immunoglobulin prophylaxis in Holland we found two cases of massive foeto-maternal hacmorrhage, while two other cases were referred to us for investigation because the child was anaemic at birth. All four women were treated with anti-D immunoglobulin shortly after delivery. Despite this treatment, all four mothers developed rhesus antibodies. The purpose of this report is to discuss the possible reasons for the therapeutic failures and to consider the future management of similar cases.

\section{Material and Methods}

Preparation and Assay of Anti-D Immunoglobulin.-Anti-D immunoglobulin was prepared from 20 litres of pooled plasma donated by 18 naturally immunized women. A $14 \%$ solution of this concentrate was found to contain $250 \mu \mathrm{g}$. of anti-D per ml. The in-vivo activity of the preparation was assessed as follows: male volunteers received an intramuscular dose of $250 \mu \mathrm{g}$. of anti-D, and 24 hours later $2 \mathrm{ml}$. of packed ${ }^{51} \mathrm{Cr}$-labelled rhesuspositive erythrocytes was injected. The erythrocyte survival curve showed that $95 \%$ of the labelled cells were cleared from the circulation within 15 hours.

Estimation of Size of Foeto-maternal Haemorrhage.Haemoglobin $F$ cell counts were done by the method of Kleihauer, Braun, and Betke (1957). Cells containing mainly foetal haemoglobin ("typical Hb F cells") were counted in 50 low-power fields (magnification $\times 100$ ) ; adult erythrocytes were counted on the same blood film at higher magnification $(x 400)$. The amount of foetal blood in the mother's circulation was calculated by the following formula (Kleihauer, 1966):

Volume of foetal blood $(\mathrm{ml})=.\% \mathrm{Hb} \mathrm{F}$ cells $\times 50$.

According to this formula a Hb F:adult cell ratio of $1: 1,000$ corresponds to a transplacental haemorrhage of $5 \mathrm{ml}$.

The accuracy of this technique was tested on five samples of adult blood mixed with various amounts of cord blood. These

\footnotetext{
- Blood Transfusion Laboratory, University Hospital, Utrecht, The Netherlands.
}

mixtures were sent to us by Professor P. L. Mollison and were counted as unknown samples in our laboratory (sce Table I

\section{TABIE I.-Accuracy of Kleihauer's Technique}

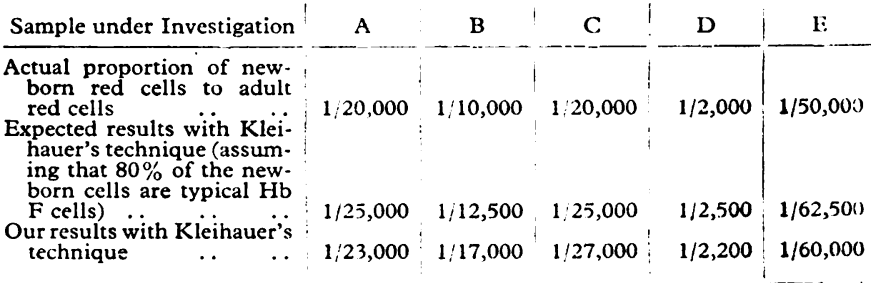

\section{Case Reports}

Case 1.-A 28-year-old secundigravida, blood group A Rh-negative, was admitted to hospital because of pre-eclampsia and a history of cerebral thrombosis. A blood sample drawn in the 35th week of pregnancy showed no rhesus antibodies. The foetal cell count indicated that if a transplacental haemorrhage had occurred it could not have exceeded $0.04 \mathrm{ml}$. In the 37 th week an attempt at amniocentesis was abandoned when blood was aspirated. Unfortunately this blood was not examined. Two days later the foetal heart sounds disappeared and five days later a macerated foetus was born spontaneously. The placenta was massively infarcted. A sample of maternal blood drawn after delivery contained $2.8 \% \mathrm{Hb}$ $\mathrm{F}$ cells, corresponding to a transplacental haemorrhage of about $140 \mathrm{ml}$. A mixed agglutination test was performed with anti-B and with anti-D serum, and it was found that the baby was $\mathbf{A}$ or $\mathrm{O}$ Rh-positive. Fourteen hours after delivery the mother received one dose of $250 \mu \mathrm{g}$. of anti-D immunoglobulin. The disappearance of the foetal cells, which took 11 days, is shown in the Chart Two months later anti-D + anti-C antibodies were found in a titre of $1: 32$ and $1: 4$, respectively (see Table II).

Case 2.-A 40-year-old secundigravida, blood group A Rh-negative, spontaneously came into labour at term. The baby was moderately asphyxic and very pale at delivery. The blood group of

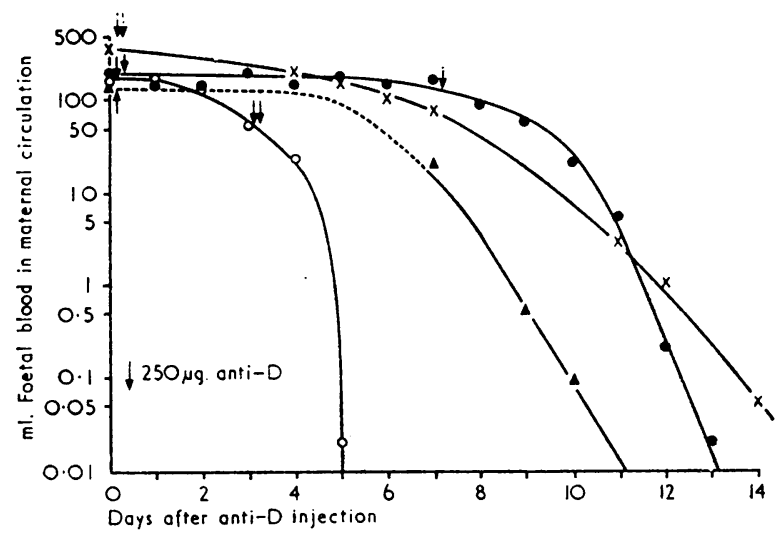

Clearance of foetal blood from the maternal circulation after administration of anti-D immunoglobulin. $\times \longrightarrow \times$ Case 2.0 Case 4. 
the child was A Rh-positive. The haemoglobin content of the blood was $8.4 \mathrm{~g} . / 100 \mathrm{ml}$., the reticulocyte count was $6.3 \%$, and a blood film showed 59 normoblasts per 100 leucocytes. Liver and spleen were not enlarged. The diagnosis of a large transplacental haemorrhage was confirmed by the Kleihauer technique. We found $7 \%$ $\mathrm{Hb} F$ cells, indicating a blood loss of $350 \mathrm{ml}$. Twenty-four hours post partum $500 \mu \mathrm{g}$. of anti-D immunoglobulin was given intramuscularly. The foetal cells were cleared from the circulation in 15 days as shown in the Chart. Two months later the titre of anti-D antibody was $1: 64$ (see Table II).

Case 3.-An 18-year-old primigravida, blood group O Rh-negative, spontaneously delivered a male infant weighing $2,960 \mathrm{~g}$. The baby was active but pale. Twenty-four hours later a blood sample showed a haemoglobin of $8.3 \mathrm{~g} . / 100 \mathrm{ml}$. and a reticulocyte count of $15 \%$. No enlargement of the liver or spleen was found. The baby's blood group was $\mathrm{O}$ Rh-positive. A maternal blood sample contained $3.5 \% \mathrm{Hb} \mathrm{F}$ cells, indicating a transplacental haemorrhage of approximately $175 \mathrm{ml}$. On the second day after delivery the mother received $250 \mu \mathrm{g}$. of anti-D immunoglobulin, and three days later an additional $500 \mu \mathrm{g}$. was given. On the sixth day after delivery no more foetal red cells could be demonstrated in the mother's circulation (see Chart). Three months later the mother's serum was found to contain anti-D antibody in a titre of $1: 16$ (see Table II).

Case 4.-The blood of a 20-year-old secundigravida, blood group A Rh-negative, was examined at 38 and 39 weeks' gestation and on both occasions was found to contain $3.6 \%$ of $\mathrm{Hb} \mathrm{F}$ cells, corresponding to a transplacental bleeding of $180 \mathrm{ml}$. At 40 weeks a baby of $2,900 \mathrm{~g}$. was delivered spontaneously. The blood group was A Rhpositive, and the haemoglobin content $12.5 \mathrm{~g} .1100 \mathrm{ml}$. A few normoblasts were seen on the blood film. Liver and spleen were not enlarged. A maternal blood sample drawn immediately after delivery contained $3.8 \% \mathrm{Hb} \mathrm{F}$ cells. Six hours later the mother was given $250 \mu \mathrm{g}$. of anti-D immunoglobulin. During the next six days the number of $\mathrm{Hb} \mathrm{F}$ cells in the maternal blood was shown not to have decreased. Therefore on the seventh day after delivery a second dose of $250 \mu \mathrm{g}$. of anti-D immunoglobulin was given. Six days later the foetal cells had disappeared from the mother's circulation (see Chart). Four months after delivery the maternal serum was found to contain anti-D and anti-C in a titre of $1: 16$ and $1: 8$, respectively (see Table II).

\section{Discussion}

Prevention of rhesus immunization by prophylactic treatment with anti-D immunoglobulin appears to be effective in practically all transplacental bleeds of small size. Whether this treatment will prove to be as effective when larger foeto-maternal haemorrhages have occurred remains to be proved. This question is of particular interest because it has been shown that the risk of immunization in bleeds of more than $3 \mathrm{ml}$. is much greater $\left(50^{\circ}\right)$ ) than in the more usual small bleeds of less than $0.25 \mathrm{ml}$. (8\%) (Woodrow and Finn, 1966).

Haemorrhages of more than $100 \mathrm{ml}$. can occur, but are very rare. So far only one case has been reported in which anti-D immunoglobulin was given (Gilliver, 1967). In this woman rhesus immunization did not occur. Unfortunately we have not been able to repeat this experience. Though our four cases were treated with anti-D immunoglobulin shortly after delivery, all four women developed rhesus antibodies. It is most unlikely that these antibodies were passively acquired as a result of the treatment. Not only were the titres higher than those immediately following the anti-D injection, but, also, in three cases there were saline antibodies, a type not found in the immunoglobulin preparation. Furthermore, in Cases 1 and 4 anti-C antibodies developed along with anti-D.

\section{Possible Reasons for Failure}

There remain three possible reasons for the failure to protect these women from immunization.

The first is that the anti-D immunoglobulin injection may have come too late. Most transplacental haemorrhages occur at the time of delivery, but in each of our cases there are indications that the bleeding had started earlier. In Case 1 the foetus died five days before delivery, and one may therefore assume that the foetal cells entered the maternal circulation at least five days before the anti-D injection was given. Moreover, it is possible that the haemorrhage occurred as a result of the attempt at amniocentesis two days before death. In Case 2 the amount of foetal blood found in the mother's circulation was approximately equal to the baby's own blood volume; therefore, the bleeding probably occurred gradually and started at least several days before delivery. In Case 3 the baby's lively appearance, together with the marked reticulocytosis, suggests that the blood loss also occurred at least a few days before birth. In Case 4 it was actually demonstrated that 180 ml. of foetal blood was already present in the maternal circulation two weeks before labour.

It is not known how long one can safely permit rhesuspositive cells to circulate in a rhesus-negative person before one has lost the opportunity to prevent immunization. The only information on this point comes from Freda, Gorman, and Pollack (1964), who found that anti-D when administered 72 hours after the injection of rhesus-positive blood still protected male volunteers from active immunization. The evidence described in our cases suggests that large amounts of foetal blood had already been present for a considerable period of

TABLE II.-Serological Findings and Foetal Cell Counts

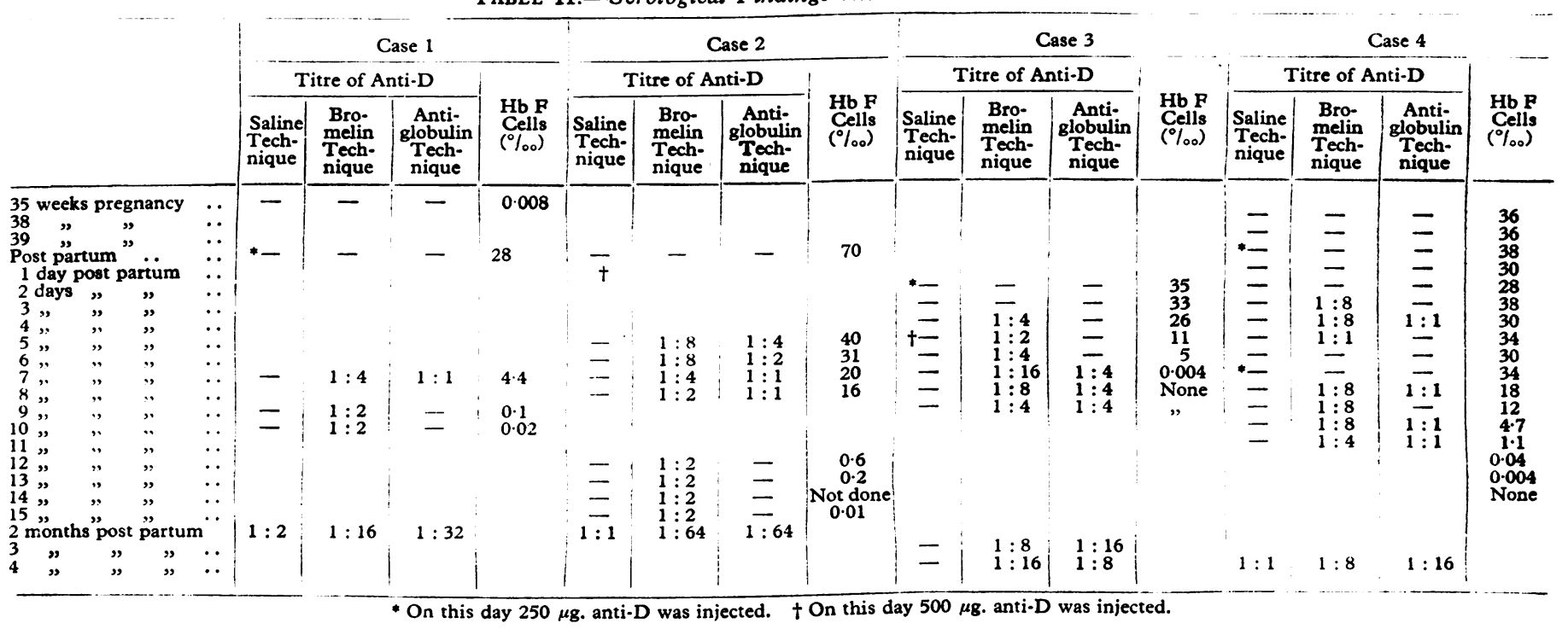


time (longer than 72 hours) before anti-D was administered, and it is possible that active immunization had started before treatment. In the case described by Gilliver (1967) the bleeding probably occurred not more than 12 hours before delivery, and it may be that the apparent therapeutic success was due to the brief exposure to the antigenic stimulus.

An alternative reason for failure to protect these women from active immunization may have been that the doses of anti-D immunoglobulin were too low in relation to the large amounts of rhesus-positive blood. Disappearance of foetal cells from the circulation took much longer (6 to 15 days) than in most transplacental bleedings, where the foetal red cells are cleared within 24 to 48 hours. In Gilliver's patient a dose of approximately $1,000 \mu \mathrm{g}$. was administered (J. C. Woodrow, personal communication). This is higher than the amount given by us (250-750 $\mu \mathrm{g}$.), and thus may account for the favourable outcome in his patient. Nevertheless, it should be emphasized thtat despite the high dose of anti-D the clearance of foetal red cells in this case took nine days (Gilliver, 1967).

Freda et al. (1964) have suggested that it is not the accelerated ciearance of foetal cells but the actual concentration of free antibody in the plasma which is responsible for the suppression of the primary immune response. In large foeto-maternal haemorrhages a considerable part of the anti-D is probably adsorbed by the foetal cells. It is therefore possible that the final concentration of free antibody was too low to bring about effective suppression. If the assumption of Freda et al. is correct, then it would seem advisable to treat large transplacental bleedings with very high doses of anti-D.

The third and last point that should be raised is whether anti-D immunoglobulin might have enhanced the immune response instead of having suppressed it. An analogous situation has been observed in experimental animals when $\operatorname{IgM}$ antibody was given with an excess of antigen. Furthermore, recent experiments suggest that low doses of IgG antibodies can also stimulate immunization (Pearlman, 1967). In humans enhancement of anti-D production has possibly been effected by the injection of serum containing anti-D saline agglutinins (Clarke et al., 1963). With anti-D immunoglobulin preparations, which contain no IgM antibody, enchantment has never been observed even under conditions when the dose was inadequate to suppress immunization (Freda, Gorman, and Pollack, 1966 ; P. L. Mollison, personal communication). In our series all four women developed rhesus antibodies. This is at variance with the general impression that after a rhesus-incompatible transfusion only $50 \%$ of the recipients are immunized (Mollison, 1967).

\section{Conclusion}

We think that our therapeutic failure is at least partly related to the timing of the anti-D injection. With respect to this one should bear in mind that most cases of large foetomaternal haemorrhages are probably the result of repetitive bleeds occurring before birth, and that they are discovered only when the diagnosis of anaemia is made in the infant. A foetus having a single massive haemorrhage is not likely to survive, and its macerated condition at birth will preclude recognition of the syndrome, unless the maternal blood is especially examined by means of the Kleihauer technique.

On the basis of the foregoing one should search for massive foeto-maternal haemorrhage in all cases where there has been unexplained intrauterine foetal death, or where the infant is anaemic at birth. Once the diagnosis is established it would seem advisable to try to avoid the high risk of immunization by administering high doses of anti-D immunoglobulin.

\section{Summary}

Four cases are presented in which a large transplacental haemorrhage (varying from 140 to $350 \mathrm{ml}$.) occurred in a rhesus-negative woman carrying a rhesus-positive foetus. Shortly after delivery each mother was treated with anti-D immunoglobulin, which resulted in clearance of the foetal red cells from the circulation within 6 to 15 days. Despite this treatment all four women developed rhesus antibodies. The two most likely reasons for these therapeutic failures are: the interval between the transplacental haemorrhage and the administration of the anti-D immunoglobulin may have been too long, or the dose may have been too low in relation to the magnitude of the bleed.

The anti-D immunoglobulin was prepared by Dr. H. W. Krijnen, at the Central Laboratory of the Netherlands Red Cross Blood Transfusion Service, Amsterdam. The in-vivo activity of the preparation was assessed at the same institute by Dr. A. E. G. Kr. v.d. Borne and Dr. E. Reijnierse. The anti-D content was kindly determined by Dr. N. C. Hughes-Jones, Wright-Fleming Institute of Microbiology, London. All serological tests were performed by Miss J. M. J. P. Matthey.

We are indebted to Professor Dr. G. J. Kloosterman, Wilhelmina Gasthuis, Amsterdam (Case 1), Professor Dr. W. P. Plate, University Hospital, Utrecht (Case 4), Dr. K. Ittman, Zeeburg Hospital, and Professor Dr. J. I. de Bruijne, Wilhelmina Gasthuis, Amsterdam (Case 2), for permission to publish the case records, and to Dr. J. van Loo and Miss P. Visser, midwife, for referring Cases 3 and 2 respectively. We gratefully acknowledge the assistance of Dr. A. W. de Groot and Dr. J. Klomp in procuring the blood samples. Dr. Phin Cohen kindly assisted in preparing the manuscript.

\section{REFERENCES}

Clarke, C. A. (1967). Brit. med. f., 4, 7.

Clarke, C. A. (1967), Brit. med.

Freda, V. J., Gorman, J. G., and Pollack, W. (1964). Transfusion (Philad.), 4, 26.

Tilliver, Science, 151, 828

Giliver, B. E. (1967). Brit. med. 7 , 3, 47. p. 76. Stuttgart.

p. 76. Stuttgart. Betke, K. (1957). Klin. Wschr., 35, 637.

Mollison, P. L. (1967). Blood Transfusion in Clinical Medicine, 4th ed., p. 303. Orford.

p. Jo D. S. (1967). 7. exp. Med. 126, 127

Woodrow, J. C., and Finn, R. (1966).' Brit. F. Haemat., 12, 297. 